\title{
Teaching Reluctant Students: Using the Principles and Techniques of Motivational Interviewing to Foster Better Student-Teacher Interactions.
}

\author{
Harvey Wells ${ }^{1}$, Anna Jones ${ }^{2}$ and Sue C. Jones ${ }^{3}$
}

\begin{abstract}
In formal learning settings there will always be instances of resistance to learning from students, resulting in either open conflict or withdrawal and consequent disillusionment on the part of both students and teachers. This paper presents a set of principles and associated practices for responding to disengagment from learning in constructive ways. This framework, motivational interviewing, is borrowed from healthcare but has been adapted for use in higher education. The model focuses on building confidence and independence and fostering engagement, thus enabling students to take responsibility for their learning. The model is student-centred and collaborative and thus fosters constructive relationships between student and teacher. This paper presents the theoretical underpinnings of the model and the ways in which it can be used in teacher-student interactions.
\end{abstract}

\section{Introduction}

Teaching is a complex activity within which a teacher must simultaneously manage the organisation of knowledge, personal relationships, group dynamics, time constraints, external demands, anxieties of students and his or her own fears or concerns. At the centre lies learning, which can be significantly influenced by the interrelationship between the teacher and the learner. This personal dynamic sits in the context of broader social factors. The aim of this paper is to outline the development of a conceptual framework for fostering collaborative relationships between teachers and students, particularly when the student is not engaged. Anyone who has been in a classroom, as a teacher or a student will understand the difficulties. While this paper is presented as a tool for use in the case of students who appear resistant to learning, it argues that the underlying principles are central to good teaching for all students. The theoretical framework has been borrowed from healthcare where it is used to help people change unhealthy behaviours. It is this focus on change that suggests its potential for use in higher education. In conceiving of learning as a process of change and teaching as facilitation of change it is possible to envisage an approach to teaching negotiated between the student and teacher. In referring to resistance and reluctance we are not championing passivity or obedience, quite the contrary - this approach aims to enable the willingness to engage and to question. It does not seek to create students who are compliant but to teach students to challenge and critique.

This paper is part of a larger project investigating the application of this framework for teaching in higher education. This project explores the conceptual framework and its application in the classroom and aims to provide a set of resources for university teachers who want to use this method in their classrooms (available at www.motivate-ed.co.uk).

\footnotetext{
${ }^{1}$ St George's, University of London \& Kingston University

2 Glasgow Caledonian University

${ }^{3}$ King's College London
} 
This paper is based upon the view that learning is a process of change (Hay et al, 2008a; Hay et al 2008b; Jarvis, 1992; Kolb and Fry, 1975; Rogers, 1961) encompassing changes in knowledge and understanding, attitudes and behaviours. Further, as a form of change, learning is not necessarily linear or unidirectional. Thus, if the teacher can work with the student rather than encouraging resistance they may be better able to promote learning.

Basing teaching approaches upon therapeutic techniques is not new. There are a number of examples of cross-fertilisation between education and psychotherapy that serve as precedents. Rowland, for example, argued, 'University teaching in general, and educational inquiry on the part of the university teachers in particular, can usefully draw on therapeutic insights' (2000, p.107). This is our starting position: that psychotherapy has something to contribute to teaching in higher education. Rogers (1957) believed that the concepts central to his Person Centred Counselling approach were useful for education. In Becoming a Person, he provides an example of teaching using his core conditions of empathy, unconditional positive regard and congruence, which both Cowan (1998) and Nolan (1998) have since advocated. Whilst this approach may be appealing, the reality is that it is not simple.

Mortiboys (2005) highlighted a number of techniques and strategies to become an emotionally literate teacher, arguing that emotions are central to the decision-making process. These techniques include the teacher becoming aware of emotions, and paying attention to how one interacts with students. This, Mortiboys argued, results in emotionally intelligent students. This is a lofty goal and is a greater aspiration than we are proposing here. Our aim is to offer principles to engage students who seem unwilling to learn, to help them become motivated to learn.

While this paper focuses upon an individual approach to students, this should not be misconstrued as an approach to teaching and learning which assumes students to be independent from their setting - personal, cultural and structural. One of the central assumptions upon which this work is based is that teaching and learning occurs in context. Moreover, while this work aims to provide teachers with strategies to work with disengaged students, this does not imply a deficit model of students. Rather, it acknowledges that students do not learn for a number of reasons that can be contextual, social, institutional, political and can be as much to do with the teacher as the student. One way of locating an $\mathrm{Ml}$ approach to student learning in context is through considering the notion of student engagement (Krause 2005; Mann 2001). Bryson and Hand (2007) describe engagement as the interaction of the student with the learning environment. This definition captures some of the complexities of the issue as it acknowledges the interaction between the individual and the environment without assuming either total and individualistic agency, nor simplistic structural determinism.

Zyngier (2007) makes the link between engagement and student learning, arguing that it can be understood at a number of levels from technical through constructivist to emancipator. He points out that a very narrow and de-contextualised definition suggests that if a student is engaged the teacher can claim responsibility but if the student is disengaged, the responsibility is placed with the student. Clearly, as Zyngier points out, it is very simplistic to define engagement in terms of student 
deficiencies. With regard to engagement, Mann (2001) outlines five positive responses: solidarity and empathy through discussion; hospitality or making students feel part of a community; safety; redistribution of power and criticality. Using MI as a teaching strategy is one step towards this as it promotes a non-judgemental, constructive and collaborative dialogue between teacher and student. As Krause (2005) points out, equipping students with strategies for taking responsibility for their learning is supportive way is one of the keys to student engagement and using these techniques is one way of achieving this.

\section{Motivational Interviewing}

Motivational interviewing (MI) is the set of principles and techniques upon which this paper is based and which have been adapted for application in a higher education setting. $\mathrm{Ml}$ is a model of psychotherapy designed around facilitating change. MI, however, makes no assumptions as to why the person has developed the attitude, but accepts the current situation and efforts are oriented in terms of negotiating a constructive approach. This is important for education as no claim is made that the student is dysfunctional. In a formal learning situation there are a set of relatively fixed constraints - timetables, deadlines, prerequisites, the needs of other students. The student and teacher must both navigate a path through these constraints, acknowledging they cannot (easily) be changed.

$\mathrm{MI}$ is a learning-based therapy designed around the process of change. Broadly, MI is 'a client-centred, directive method for enhancing intrinsic motivation to change by exploring and resolving ambivalence.' (Miller and Rollnick, 1991: 25). Essentially, it is a method of effective communication to engage people in a process of change, based on several key ideas: motivation, resistance, ambivalence, self-efficacy and empathy. Each will be explored to make sense of their application in a higher education context.

\section{The Traditional View of Motivation}

The traditional view of motivation in healthcare is that it is a static disposition or trait (Heckhausen \& Heckhausen, 2008). People are either motivated to change their behaviours or they are not, it is down to them. A person must be intrinsically motivated (Lepper, 1988) to change their behaviours, such as stopping smoking or increasing exercise, and if they do not, then they were not sufficiently motivated. This perspective can be used as a defence if treatment does not work: "her treatment was unsuccessful because she wasn't fully motivated." The practitioner is kept safe from any painful self-reflection: "was there anything I could have done differently?"

Similar difficulties have been observed in higher education: students are either motivated to learn or they are not. Teachers are also able to use the motivational defence: "that student didn't learn because he didn't try hard enough." Barnett (2007) identified that students have a 'will to learn'. The implication of this is that those people who do not have this will do not enter higher education or drop out. This perspective keeps teachers safe: if a student does not engage, it is their fault: they were not sufficiently motivated to learn. Prochaska \& DiClemente (1983) changed the way in which motivation is viewed. 


\section{The Cycle of Change}

Prochaska \& DiClemente (1983) developed the Transtheoretical Model of Change, commonly known as the 'Cycle of Change'. They discovered that people change by undergoing a series of cognitive and behavioural changes. However, rather than a linear stage model, they noted that people move back and forth through the stages and may even spiral around the stages before achieving lasting change. The Cycle of Change identified six discrete stages: precontemplation, contemplation, preparation, action, and maintenance (with the sixth being relapse which can occur during any of the other stages).

Precontemplation is the first stage of the model, during which, the person is unaware their behaviour is problematic. In terms of education, they may be unaware that there are any problems with their approach to learning. In this stage the student has no awareness of a need to learn differently. This student is happy to maintain the status quo: "I don't need to change."

The contemplative stage is when the person begins to recognise a problem with their behaviour. For a student this may be characterised by a realisation that they are required to go beyond what they already know, or change approaches to learning that might have worked previously. This may be prompted by an external event, such as failing an exam or an assignment, or it may be a feeling of not keeping up with other students. However, at this stage it is important to recognise that the person is thinking about changing, but has not yet changed.

The preparation stage is when the person explores possible resources to use to support a change in their behaviour; often stimulated by a greater awareness of potential for failure if they do not change their approach. For the student this may be seeking out possible resources and actions to help support a change. This may involve seeking support from teachers, peers, or attending a student support service.

The action stage is when an individual changes their behaviour. For the student this would be through engaging in behaviours that offer greater opportunity for learning to occur. They may experience heightened feelings of empowerment and self-esteem, but this behaviour may be short lived. Perhaps they studied for a particular exam or assignment, but it has not changed their approach to learning in general. It is therefore important for the student to continue this newly learned behaviour, in which they maintain patterns that enable learning.

Anyone who has tried to change will know how difficult this is to achieve and maintain. The most common outcome of any behaviour change is relapse (Rollnick \& Miller, 1995). When we are stressed we tend to return to older well-established patterns. A person may have given up smoking, stopped drinking or started studying in a productive way; a stressful week may result in picking up a cigarette, a pint of lager or last-minute cramming. Old behaviours are like a well-trodden path. New behaviours require hard work and repetition for them to take hold, for them to become familiar and trusted. Once the person relapses, they may re-enter the cycle at any stage and may experience feelings of helplessness and guilt. 
How can a greater understanding of this cycle help teachers support the process of learning? Each of the stages suggests utilising a certain approach to engage the learner. However, before we discuss these approaches, we must consider the concepts that are important for teachers to understand in order to encourage change in approaches to learning.

\section{Motivation}

Motivation arises from interaction between a person and an idea or object. This object may be the subject being studied, or a teacher. Motivation will fluctuate over time but it is proportional to the relationship between the person and the object. Rollnick and Miller (1995) identified that in psychotherapy motivation is a product of the relationship between the therapist and the client. The client will be motivated if the therapist engages them, remains non-judgemental and supportive. The same principles can be applied to education: teachers who engage their students in their learning are likely to develop a more effective relationship with their students. Therefore, students are more likely to be motivated to attend class, participate and subsequently learn.

The importance of the relationship in any learning context holds intuitive appeal. We are motivated by ideas we find interesting and de-motivated by subjects that we perceive as dull or unimportant. We are motivated by people we respect and hold in regard and we are de-motivated by people we do not value or respect. It is with teachers and subjects that we do not enjoy where resistance to learning is most likely to surface. Freud (1914) seems to have concurred:

"It is hard to decide whether what affected us more and was of greater importance to us was our concern with the sciences that we were taught or with the personalities of our teachers" (pp.242).

Therefore, the role of the teacher in Higher Education is critical to enhancing the motivation of students. Barnett stated that 'the primary responsibility of teachers in higher education is to sustain and develop the student's will to learn.' (2007, pp.210). Failing to effectively engage students may result in behaviours that are actively resistant towards learning.

\section{Resistance}

The first key to change is to manage resistance so it does not become a barrier (Miller \& Rollnick, 2004). Resistance is evoked when there is disconnection between the person and the object. This is most easily understood in terms of interpersonal dynamics: when the teacher and student are not working together effectively. Typically, this happens in psychotherapy when the approach taken by the therapist does not match the person's stage of change. Essentially, if the change is too much or too fast then the most likely response is resistance.

There are a number of different types of resistance that can arise between student and teacher. The student may argue with the teacher. This arguing is not the constructive discussion of ideas but more likely to be centred upon more personal aspects such as the teacher's expertise or integrity. The student may deny their 
predicament or be unwilling to recognise problems, cooperate, or accept responsibility. Finally, the student may resist by not coming to class, being inattentive, not responding to communications, or actively side-tracking a conversation.

Whilst resistance arises out of the interpersonal interaction, it is the teacher's responsibility to manage. Resistance suggests that the strategy being used is not appropriate for that person. Therefore, the teacher must find alternative strategies. If the teacher persists using the same strategy the student is likely to become more resistant. However, it is important to bear in mind that resistance does not suggest that the person is unwilling to change. Change is difficult so resistance is normal.

\section{Ambivalence}

Change requires energy, commitment and a risk that the change may not work out and people have mixed feelings about change even when it is desired. Therefore, ambivalence to change is normal and resolving this ambivalence is vital to achieving change (Rollnick \& Miller, 1995). Resolving ambivalence is achieved by exploring the discrepancy between current behaviour and future goals. For example, a student may have a goal of obtaining a first class degree but is struggling to become motivated in studying for an exam. Holding these two ideas together shows there is a discrepancy. Allowing the student to weigh up these positions gives them an opportunity to come to a conclusion about what they need to do. Another strategy is to explore the good and not so good aspects of their current behaviour: "What are the good things about studying for this exam? What are the not so good things?" Exploring extremes is also a useful way of resolving ambivalence: "What is the best thing that could happen if you do not submit an essay? And what is the worst thing?" This allows the student to reach a conclusion about the potential consequences of their behaviour without the teacher having to state this for them.

\section{Self Efficacy}

Self efficacy refers to a person's perception of their own competence (Bandura, 1977 ) and increases with successful performance. When students experience success with assignments and exams their feelings of confidence and competence increase. As learning tasks become more advanced the student must feel sufficiently confident and competent to be able to attempt the task. However, when students experience failure they may lose confidence in their ability. At this point it is important for teachers to help build the students confidence back, not by telling them how good they are, but by facilitating the student to evaluate their own performance. This way the student retains control over their performance and is not reliant on others for evaluation.

\section{Empathy}

It has been repeatedly demonstrated that psychotherapist empathy is fundamental to developing a working alliance with a client therefore vital to facilitating change (Wampold, 2001). Empathy has been defined as the capacity to think and feel oneself into the inner life of another person' (Kohut, 1984, p.82). Baron-Cohen (2003) provides a useful distinction for the purposes of this paper; arguing that there 
are two components to empathy: one cognitive and one affective. The cognitive component refers to the ability to understand the feelings of another and to take their perspective. The affective component refers to the appropriate emotional response to the other person's emotional state. The cognitive component is important to both psychotherapy and to our approach to teaching. The second aspect, the emotional response, however, will be different depending on whether the context is therapeutic or educational. A therapeutic response using empathy would aim to deepen the emotional awareness of the client, encouraging a deeper exploration of their emotional world. An educational response would aim reveal thoughts and feelings that may be preventing effective learning.

The idea behind empathy for the MI approach is that understanding and acceptance facilitates change. Through the use of empathy and conveying the appropriate response, the teacher shows the student that he/she understands their behaviour. Rather than judging, blaming or confronting the student, the teacher allies themselves with the student, keeps resistance low, facilitating the change process.

\section{Using MI to Engage Students}

Examining the stages of change model suggests ways to interact with students that may encourage more effective approaches to learning. Each of these stages will be discussed in light of the strategies that can be used with students in this stage of change.

Students who are precontemplative are not aware that their behaviours are blocking learning. Confronting students who are in this stage is likely to result in greater resistance and withdrawal. A teacher should aim to engage the student in discussion about the student's goals. It is important that the teacher engage the student as an adult (Berne, 1978) to increase their self-efficacy. The teacher should aim to help the student to discover their own reasons for doing the course or programme without imposing the teacher's own perspective. This can result enhancing the student's motivation to learn. The aim at this stage is to move the student to start thinking about change.

Students in the contemplative stage are aware that they are not engaging in effective learning behaviours but are yet to change. Once the student has become aware that their behaviour is not effective for learning the aim is to help the student to think about how they would like to change. The teacher's role is to help the student consider possible resources and options available. Rather than suggest possibilities, MI suggests it is more helpful to encourage the student to think for themselves. For example, ask the student what has worked well for them in the past. The teacher can help broaden their awareness by asking what strategies their peers use to learn.

The aim of the preparation stage is to develop a plan of what the student thinks they will have to do in order to study effectively. It may be easier to set a goal particular to a specific task. As the teacher, you may feel that the steps identified in their plan are not sufficient in order to be successful in their new learning behaviour. In this situation, you can offer the student your thoughts: "I have some concerns about the plan you have suggested. Would you like to hear my thoughts?" This allows the teacher to share their concerns, but for the student to retain choice and control. 
The action stage is when the student acts upon their plan. The teacher's role is to support the student's move towards action and help them to overcome any obstacles. These incidents can prevent the student from maintaining their new learning behaviours and lead a student to lapsing into old ineffective patterns.

If the student is maintaining the new effective learning strategies, the teacher's task is to help the student continue that new behaviour. This can be helping the student reflect on the different outcomes between the old and new methods of learning. This has the impact of increasing the discrepancy between the old and the new and should help increase the motivation of that student to maintain their new behaviour. It is generally better to encourage students to evaluate their own behaviour as it is more empowering and more important than one teacher's evaluation. However, it is hard to avoid. Rather than evaluate the student's result, the teacher should aim to elicit the student's response to the assessment result. For example, avoid: "You got a B. This is good but you could do more." Try to facilitate the student reaching their own conclusion: "I got a B. This is good but I could do more". This second statement is self-motivating, whereas the first is judgemental.

If the student reverts to ineffective learning behaviours the teacher's role is to help the student treat the relapse as a learning experience and not as one that is shameful. It would be easy to blame the student: "You didn't study and you failed! What did you expect?" Instead, use exploratory questions to develop the discrepancy between what they expected and what happened. Resolving this discrepancy should result in increased awareness and enhanced motivation.

\section{Limitations of the Framework}

There are a number of limitations with this approach. The first is that it was developed in a healthcare setting and therefore the techniques are easier to implement one-to-one work or in smaller groups than they are to large classrooms. However, the principles remain applicable to larger groups and can be used in any setting. Finally, suggesting utilising therapeutic approaches to teaching can create anxiety that the intention is to turn intelligent, dynamic students into emotionally vulnerable, dependent children (Ecclestone \& Hayes, 2009). This is not our intention, nor to turn teachers into therapists. The techniques and approaches outlined within this paper support the engagement of students and may help teachers who are struggling with students who appear not to learn.

\section{Potential Benefits}

There are numerous benefits to using this approach. It links well with the studentcentred agenda by empowering the student to be responsible for their own learning. Through enabling students to identify their goals and the best ways of achieving these goals in ways that are empowering and respectful, Ml techniques enable autonomous learners to navigate a pathway through extraneous factors present in any formal education setting. 
This in turn should lead to greater student satisfaction with learning. This approach readdresses some of the power imbalances between students and teachers. It places the student and teacher in collaboration with each other. Each has their own expertise, which come together to result in positive learning experiences. In this way learning can be co-constructed in ways that are mutually beneficial. This collaboration should avoid resistance as potential conflicts can be resolved and explored before they get out of hand. Finally, this approach will help teachers manage their frustration when teaching students who appear not to want to learn.

\section{Conclusions and implications}

The use of Ml for teaching in higher education outlined in this paper has provided an overview of the potential value in enabling students to learn more effectively, particularly those who appear resistant. We have adapted the conceptual framework in order to apply it to an educational setting and acknowledge that in doing some challenges emerge. However, central to this approach is to avoid a situation where the response is resistance and Ml has the potential to achieve this. It is the teacher who can facilitate an alternative response to student resistance. This can be done through a constructive avoidance of confrontation in which new perspectives are invited but not imposed and the student is seen as a valuable source in finding solutions. Key to managing change is resolving ambivalence towards that change, minimising the resistance to learning and developing the means to support the students' self-efficacy.

The implications of this research are that although the techniques require some training and effort, they provide an approach in the teacher's toolkit which responds to reluctant learners in ways that are positive and collaborative as is appropriate in a higher education context. This approach can be used for students, in research supervision and can also be used in an academic development context. The application of motivational interviewing in an educational context is in its infancy and there is considerable scope for further research in the evaluation of its efficacy and refinement of the approach.

\section{Acknowledgements}

Our thanks to SEDA and to King's College London for grants that made the research and development work upon which this paper is based possible. Thanks also to Simon Lygo-Baker for his comments on an earlier version of this paper. 


\section{References}

Bandura, A. (1977) Self-efficacy: Toward a unified theory of behavior change. Psychological Review, 84, 191-215

Barnett, R. (2007) A Will to Learn: Being a Student in an Age of Uncertainty. Society of Research into Higher Education \& Open University Press: Maidenhead.

Baron-Cohen, S. (2003). The Essential Difference: The Truth about the Male and Female Brain. London: Basic Books

Berne, E. (1978). Games People Play. New York: Grove Press.

Bowlby, J. (1969). Attachment, vol. 1 of Attachment and loss, (2 ${ }^{\text {nd }}$ edition, 1982). London: Hogarth Press.

Bryson, C. and Hand, L. (2007) The role of engagement in instiring teaching and learning, Innovations in Education and Teaching International, 44:4, 349-362

Carless, D. (2009) Trust, distrust and their impact on assessment reform.

Assessment and Evaluation in Higher Education. 34(1) 79-89

Cowan, J. (1998). On Becoming an Innovative University Teacher: Reflection in Action. Buckingham: SRHE/Open University Press.

Ecclestone, K. \& Hayes, D. (2009). The Dangerous Rise of Therapeutic Education. New York: Routledge

Freud, S. (1914) Some reflections on schoolboy psychology, SE XIII, 239-244.

Hay, D.B., Wells, H. and Kinchin, I.M. 2008 a). Quantitative and qualitative measures of student learning at university level. Higher Education. 56:221-239

Hay, D. B., Kinchin, I., Lygo-Baker, S.(2008 b). Making learning visible: The role of concept mapping in higher education, Studies in Higher Education, 33:3, 295 - 311

Heckhausen, J \& Heckhausen, H (Eds). (2008). Motivation and Action (2nd ed.).New York, NY, US: Cambridge University Press.

Jarvis, P. 1992. Paradoxes of learning.San Francisco, CA: Jossey-Bass.

Krause, K-L. (2005) Seriouls thoughts about dropping out in first year: Trends, patterns and implications for higher education, Studies in Learning, Evaluation, Innovation and Development, 2(3) 55-68

Kohut, H, (1984). Edited by A. Goldberg \& P.E. Stepansky. How Does Analysis Cure?. Chicago: University of Chicago Press

Kolb, D., \& R. Fry. 1975. Towards an applied theory of experiential learning. In Theories of group processes, ed. C.L. Cooper. London: J. Wiley and Sons. 
Lepper, M. R. (1988). Motivational considerations in the study of instruction. Cognition and Instruction, 5, 289-310.

Mann, S. (2001) alternative perspectives on the student experience: Alienation and engagement, Studies in Higher Education, 26:1, 7-19

Miller, W.R. \& Rollnick, S. (1991). Motivational interviewing: Preparing people for change. New York: Guilford Press.

Miller, W.R. \& Rollnick, S. (2004) Talking Oneself Into Change: Motivational Interviewing, Stages of Change, and Therapeutic Process. Journal of Cognitive Psychotherapy, Volume 18, Number 4, pp. 299-308

Mortiboys, A. (2005). Teaching with Emotional Intelligence. London: Taylor \& Francis Ltd.

Nolan, J. (1998). The Therapeutic State: Justifying Government at Century's End. New York: New York University Press.

Paul, R.W. 1993. Critical thinking: What every person needs to survive in a rapidly changing world. Santa Rosa, CA: Foundation for Critical Thinking.

Prochaska, J.O. \&DiClemente, C.C. (1983). Stages and processes of self-change of smoking: toward an integrative model of change. Journal of Consulting \& Clinical Psychology; 51(3):390-5.

Rogers, C. (1961). On Becoming a Person: A Therapist's View of Psychotherapy. London: Constable.

Rowland, S. (2000). The Enquiring University Teacher. Buckingham: SRHE/Open University Press.

Rollnick S, \& Miller, W.R. (1995). What is motivational interviewing? Behavioural and Cognitive Psychotherapy, 23, 325-334.

Swift J.K, \& Callahan J.L. (2009) The impact of client treatment preferences on outcome: a meta-analysis. Journal of Clinical Psychology; 65(4):368-381.

Wampold, B.E. (2001). The Great Psychotherapy Debate: Models, Methods and Findings. London: Lawrence Erlbaum Associates.

Zyngier, D. (2008) (Re)conceptualising student engagement: Doing education not doing time, Teaching and Teacher Education, 24, 1765-1776. 